\title{
Nghiên cứu toàn cảnh phản ứng của Việt Nam trước đại dịch COVID-19
}

\author{
Nguyễn Phúc Khánh Linh \\ Trường ĐH Phenikaa
}

Trung tâm ISR - Trường Đại học Phenikaa (7-4-2020; https://isr.phenikaa-uni.edu.vn/chitiet/tintuc 20192222758 84/nghien-cuu-toan-canh-phan-ung-cua-viet-nam-truoc-dai-dich-covid-19) - Hiện nay, cả thế giới đang đối mặt đại dịch toàn cầu COVID-19 do virus SARS-CoV-2 gây ra. Đứng trước tính cấp bách của sự việc, các nhà nghiên cứu tại Trung tâm ISR, trường Đại học Phenikaa đã sớm xuất bản một nghiên cứu đánh giá tổng quát nhất về khả năng đối phó dịch bệnh của Việt Nam.

Bài viết Policy Response, Social Media and Science Journalism for the Sustainability of the Public Health System Amid the COVID-19 Outbreak: The Vietnam Lessons [1] của nhóm nghiên cứu Trung tâm ISR được công bố trên tạp chí Sustainability [2018 CiteScore = 3.01; 2018 JIF = 2.592; H-index SCImago 53, Q2].
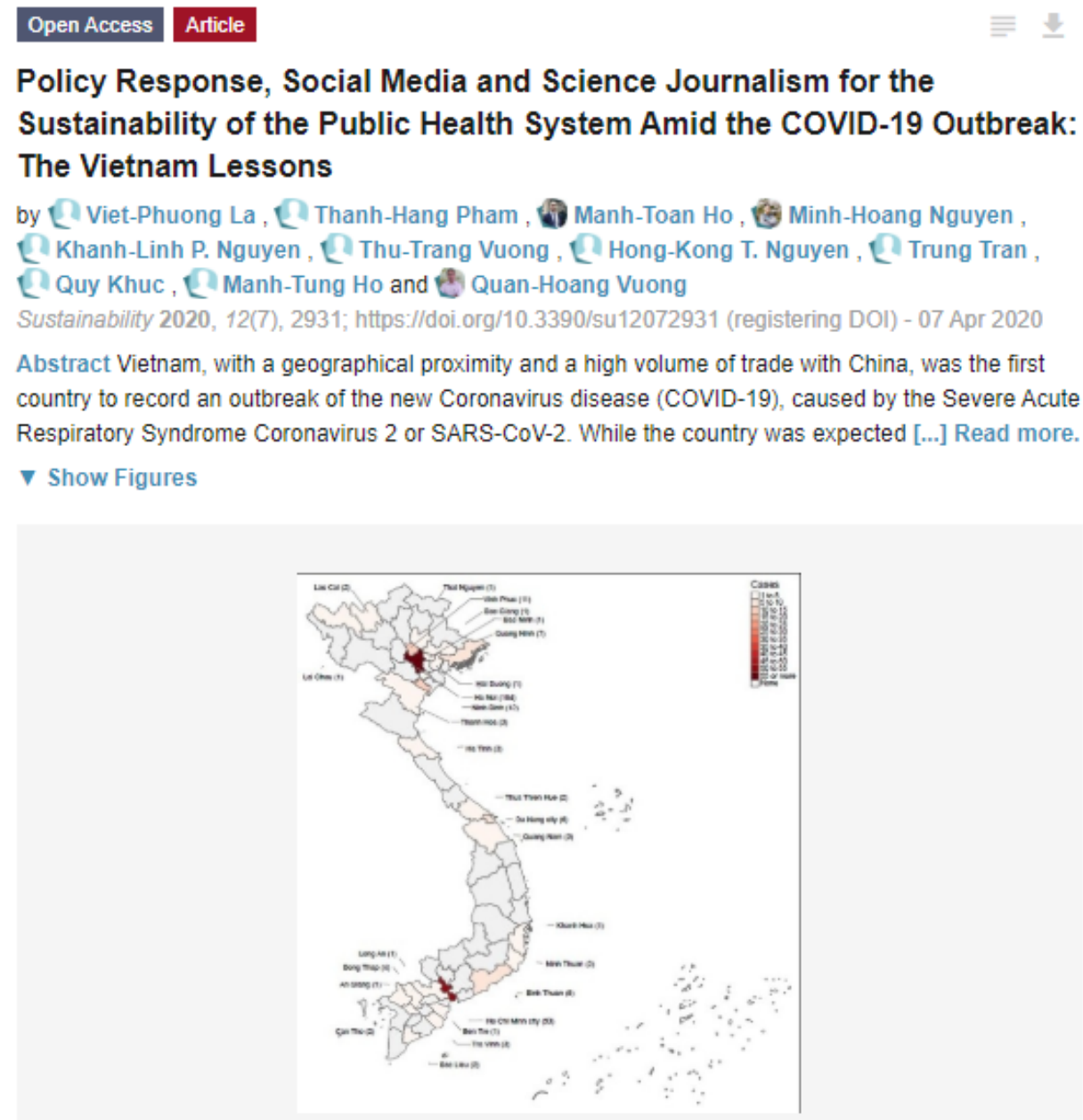

Nghiên cứu COVID-19 trên Sustainability, tháng 4-2020 
Nghiên cứu tập trung phân tích tình hình về các phản ứng chính sách, sự tương tác phương tiện truyền thông xã hội và xuất bản khoa học tại Việt Nam kể từ khi các thông tin về "dịch viêm phổi lạ" xuất hiện tại Trung Quốc cho đến nay. Một công cụ thu thập dữ liệu web đã được thiết kế riêng để sử dụng quét và thu thập các tin tức liên quan đến COVID-19 từ các trang truyền thông chính thức trong khoảng thời gian từ đầu tháng 01-2020 đến ngày 04-04-2020.

Dựa trên 14.952 tin tức thu thập được, nhóm tác giả cho thấy tại sao Việt Nam có thể ứng phó với COVID-19 hiệu quả dù là một quốc gia có nguy cơ lây nhiễm cao do vị trí địa lý và mối quan hệ sát với Trung Quốc, nơi dịch bệnh bùng phát đầu tiên. Ngay từ rất sớm, chính phủ Việt Nam đã sớm đưa ra các chỉ thị để ứng phó với dịch bệnh, đồng thời các đơn vị truyền thông cũng bám sát và đưa tin liên tục về dịch.

Nỗ lực ứng phó kịp thời này cũng được củng cố sức mạnh nhờ các nhà khoa học Việt Nam liên tục đưa ra các phân tích, đánh giá tình hình trên truyền thông, tạo ra nguồn thông tin tin cậy trên mạng xã hội. Giai đoạn sau này, sự quyết liệt tiếp tục được duy trì nhờ các chính sách cách ly, giãn cách xã hội. Bên cạnh đó, một số bài báo khoa học về các ca bệnh đầu tiên từ Việt Nam cũng tiếp tục mang lại các thông tin quan trọng. Đặc biệt, đóng góp của các nhà nghiên cứu cũng là các sáng chế kịp thời trong giai đoạn này như nước rửa tay sát khuẩn, buồng khử khuẩn.

Nghiên cứu đã rút ra được các bài học quan trọng dành cho các quốc gia đang đối diện với đại dịch, cũng như cho sự chuẩn bị để đối phó với khủng hoảng sức khoẻ cộng đồng trong tương lai. Xuất bản nghiên cứu phản ánh tinh thần chung tay đóng góp chủ động trước sự kiện có ảnh hưởng sâu rộng toàn câu, bên cạnh ý nghĩa lao động khoa học. 


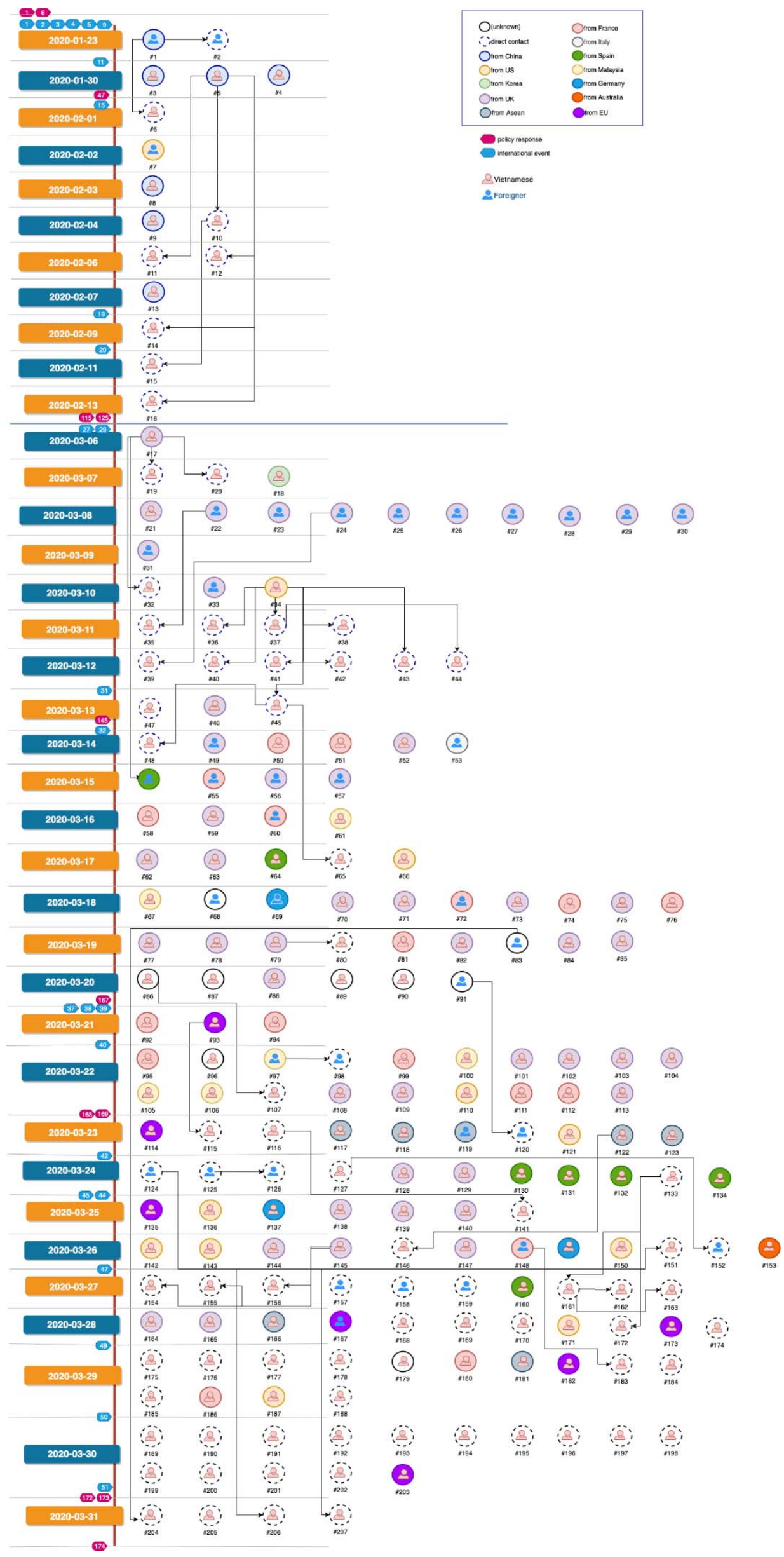


Biểu đồ các ca nhiễm bệnh, chính sách ưng phó, sự kiện quốc tế, theo trinh tự thời gian từ ca nhiễm bệnh số 1 đến ca số 207 [1].

Trong lời đề tựa của bài, nhóm nghiên cứu chia sẻ:

"Chúng tôi xin dành tặng công trinh nghiên cứu này cho Tổ Quốc của minh, đất nước Việt Nam, cho Chính phủ, và cho người dân Việt, vì tất cả những điều dân tộc chúng ta đã chung tay cùng làm trong cuộc chiến chống COVID-19. Chúng tôi xin bày tỏ sự đồng cảm sâu sắc với những người bị ảnh hưởng bởi dịch bệnh này, và xin gửi sự trân trọng đến các bác sỹ và nhân viên y tế, những người dưng cảm xả thân giúp đỡ các bệnh nhân. Chúng tôi mong rằng giai đoạn khó khăn này cho tất cả chúng ta sẽ sớm qua."

Tiếp tục hoàn thiện từ bản thảo đầu tiên [2], Trung tâm ISR, với sức vóc khiêm tốn của mình, hân hạnh được đóng góp một trong những nghiên cứu xã hội sớm nhất về COVID-19 từ Việt Nam, chung tay với thế giới trong công cuộc bảo vệ sức khỏe loài người, góp phần làm giảm bớt tổn thất và tăng thêm giá trị của đâu tư khoa học [3].

\section{Tài liệu tham khảo:}

[1] La VP, Pham TH, Ho TM, ..., Vuong QH. (2020). Policy Response, Social Media and Science Journalism for the Sustainability of the Public Health System Amid the COVID-19 Outbreak: The Vietnam Lessons. Sustainability, 12(7), 2931; DOI:10.3390/su12072931

[2] La VP, Pham TH, Ho TM, ..., Vuong QH. (2020). Policy response, social media and science journalism for the sustainability of the public health system amid COVID-19 outbreak: The Vietnam lessons. SocArXiv Preprints, DOI: 10.31235/osf.io/cfw8x.

[3] Vuong QH. (2018). The (ir)rational consideration of the cost of science in transition economies. Nature Human Behaviour, 2(1), 5; DOI:10.1038/s41562-017-0281-4. URL: https://www.nature.com/articles/s41562-017-0281-4. 